\title{
Ulcerative Colitis and Pregnancy
}

\author{
A. Alakkari and C. O'Morain \\ Adelaide and Meath Hospital, \\ Trinity College Dublin \\ Ireland
}

\section{Introduction}

Ulcerative Colitis (UC) is a chronic inflammatory condition that frequently affects men and women of childbearing age. Concerns are often raised by both patients and clinicians regarding the effects of the disease and its treatments on reproduction and lactation.

Many studies have examined fertility in UC patients in comparison with the general population. Most of these have not demonstrated a significant difference between the two groups. The observed decrease in fertility in some reports was largely attributable to patient choice, and the use of certain drugs such as sulfasalazine in men. Decreased fertility was also reported in women who have undergone surgery for their disease.

Pregnancy is considered high risk in patients with UC. Numerous studies have described the obstetric and neonatal outcomes of these patients, and reported similar pregnancy outcomes in comparison to the general population. However some population-based studies have found an increased incidence of low birth weight and preterm delivery in UC patients. This observed difference seems to be mainly related to disease activity and severity during pregnancy and the appropriate treatment required. On the other hand pregnancy does not appear to increase the risk of disease relapse or severity. The course of UC during pregnancy is partly determined by its activity at conception. Therefore UC patients should be advised to attempt to conceive during periods of disease remission.

Patients are often concerned about the safety of UC pharmacotherapy during pregnancy and lactation. Some patients choose to discontinue their maintenance therapy at least until the birth of their baby while others rely on their treating clinician to make the appropriate and safe decision regarding their treatment. Two issues have to be considered in this setting; first is the relative safety of the drug and secondly the benefit risk ratio of its use in pregnancy and lactation. A large amount of safety data is available on drugs that have been in use for decades, however modern medicine has witnessed the introduction of new therapeutic agents that have revolutionized the treatment of inflammatory diseases but there is limited data available regarding their safety during pregnancy and breast feeding.

The topic of UC and pregnancy is quite complex involving a range of issues including the effects of both the disease and its treatment options on fertility, pregnancy and lactation, in addition to the effects of pregnancy and lactation on the course of the disease. The aim of this chapter is to review the available data and discuss this topic in more detail. 


\section{UC and fertility}

There are a number of considerations when discussing the relationship between UC and fertility including the effects of the disease and the medical and surgical management options on both male and female reproduction and the risk of infertility. Infertility is defined as failure to conceive after one year of regular unprotected intercourse.

A number of studies have suggested that male fertility in UC is comparable to the general population. A survey of 62 men with UC and 140 controls found the number of pregnancies in the UC group was not statistically different to that in the control group. Fecundability (the probability of pregnancy per menstrual cycle with unprotected intercourse) was similar in the two groups [1]. A case control study of 1400 patients by Moody et al demonstrated no significant difference in the mean number of children born to male patients with UC compared to the general population [2].

Fertility rates decline in male patients following ileal pouch anal anastomosis (IPAA) for UC. In a retrospective review of 111 patients by Heuting et al [3] the incidence of sexual dysfunction after IPAA was reported at $20 \%$. A smaller prospective study of 18 patients by Berndtsson et al [4] showed loss of ejaculation in $<5 \%$ of male patients following IPAA. However in both studies the patients reported overall satisfaction with their quality of life including overall sexual function following surgery. Gorgun et al assessed sexual function in 122 male patients who underwent IPAA between $1995-2000$ using the validated International Index of Erectile Function (IIEF) scoring instrument. This index scale examines sexual function in five categories: erectile function, orgasmic function, sexual desire, intercourse satisfaction and overall satisfaction. There was a statistically significant improvement in the scores of 4 categories following surgery with an increase in the mean erectile function score by 2.12 points $(p=0.02)$ after IPAA [5].

Initial studies demonstrated infertility rates of up to $49 \%$ among women with UC, which is higher than documented for the general population (7\%-12\%)[6]. More recent studies have shown that female UC patients who have not had surgery have fertility rates comparable to the general population, and this largely reflects improvement in the medical management of UC over the years, leading to better control of disease activity, general health and reproductive function. In a study comparing 290 women with UC to 661 non IBD controls, Olsen et al found equal fecundability ratios ( $F R=1.01)$ in the two groups, but FR dropped to $0.02(p<0.001)$ after IPAA, figure 1 demonstrates the results of the study [7]. Johnson et al confirmed these findings in a study showing $13.3 \%$ infertility rates in UC patients who are medically managed compared to $38.6 \%$ infertility rates in UC patients following IPAA, $\mathrm{p}<0.001[8]$.

\subsection{Drugs used for UC and fertility}

Medical management of UC involves the use of a range of pharmacological agents with variable effects on fertility in males and females. Sulphasalazines and 5-aminosalicylates (5ASA) are often used for maintenance of disease remission in UC. Both rat and human studies have demonstrated reduced male fertility during the use of sulphasalazine due to its adverse effects on sperm count, morphology and motility. These effects are secondary to the non-therapeutic sulphapyridine moiety and are completely reversible on cessation of the drug $[9,10]$, or replacing it with a different 5ASA [11]. There are no reports of reduced female fertility with the use of sulphasalazine. 
Corticosteroids are used to induce remission during exacerbations of UC. They have been shown in rat studies to depress serum testosterone levels, but have no effect on gonadotropin levels [12]. Serum testosterone levels returned to normal on withdrawal of steroid treatment. Lerman et al demonstrated similar effects on fertility in male rats, although no change was seen in sperm number and motility [13]. There is limited data on the effects of exogenous steroids on male fertility in humans. A study by Roberts et al, suggested that an increase in endogenous cortisol levels observed following strenuous exercise was associated with a subsequent decrease in sperm concentration [14]. Therefore, steroids should only be used short term to control disease activity. The use of steroids for different diseases in females has not been associated with impaired fertility.

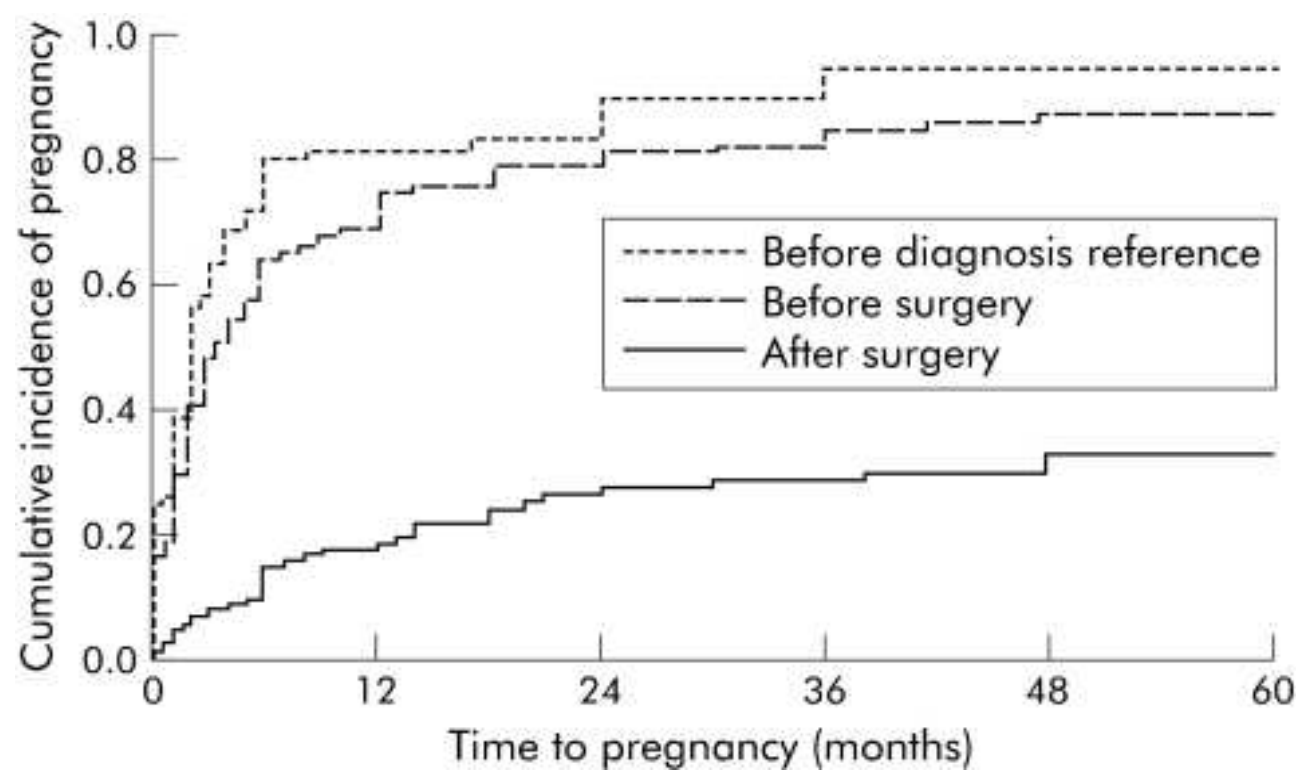

Fig. 1. Fecundability ratio in patients with ulcerative colitis before and after diagnosis, and after ileal pouch anal anastomosis compared with healthy controls. Reprinted from Olsen and colleagues [7]

Immunosuppressants are frequently used in the management of UC as steroid-sparing drugs to maintain disease remission. Their effects on male fertility in humans are controversial. Although the use of Mercaptopurine (MP) in male mice has been associated with reduce fertility [15], it has not been shown to affect sperm count or quality [16]. Francella et al, in a retrospective review of 485 IBD male and female patients found that the use of MP did not result in a statistically significant difference in conception failure compared to IBD patients not receiving MP [17]. Review of the long-term use of immunosuppressants such as Azathioprine in renal transplant patients has also shown no obvious effects on fertility in both males and females [18].

The use of anti-TNFa agents in the management of UC has been increasing over the last decade with accumulating evidence to support its beneficial effects. There are no human data on the effects of biologic therapy on fertility but data on its safety during pregnancy is 
increasing (this will be discussed in more detail later). Animal studies have demonstrated no adverse effects on both male and female fertility [19].

\section{UC and pregnancy}

\subsection{The effects of UC on pregnancy}

Pregnancy is considered high risk in patients with UC, and this is primarily related to disease activity at conception and during pregnancy. The overall outcome of pregnancy in $\mathrm{UC}$ is comparable to the general population however active disease during pregnancy especially when severe results in adverse pregnancy outcomes. This has been confirmed by a number of studies. A Danish population based study demonstrated no increased risk of low birth weight and intrauterine growth retardation in patients with $\mathrm{UC}$, however the risk of preterm delivery was increased when the first hospitalization for UC took place during pregnancy (odds ratio $=3.4,95 \%$ confidence interval $=1.8-6.4$ ) [20]. A retrospective review of 98 pregnancies in IBD patients by Federkow et al, found a statistically significant higher rate of preterm delivery $(p<0.01)$ than the rate of the control group. The risk was further increased when a disease exacerbation occurred during pregnancy [21]. Bush et al, in a case control study of 116 pregnancies in IBD patients demonstrated an increased risk of low birth weight in the UC group compared to the Crohn's disease (CD) group (19\% vs. 0\%, p = $0.002)$, with flares during pregnancy associated with an increased risk for preterm delivery ( $27 \%$ vs. $8 \%, p=0.02)$ and LBW (32\% vs. $3 \%, p=0.003)$ [22]. A population based cohort study of 239773 pregnant women including 756 women with IBD, by Kornfeld et al, supported the increased risk of adverse pregnancy outcomes such as preterm delivery, low birth weight, small for gestational age, and cesarean section in pregnant women with IBD [23]. Therefore control of disease activity during pregnancy is imperative for the well being of the mother and the baby.

\subsection{The effects of pregnancy on UC}

Pregnancy was initially thought to lead to improved control of disease activity during the gestational period as a result of the relative suppression of the mother's immune system to allow fetal development. However, evidence suggests that gestational disease activity is influenced by factors other than the physiological state of pregnancy. Disease activity during pregnancy is determined by activity at conception. Patients who conceive during disease remission have relapse rates comparable to non-pregnant UC patients over a ninemonth period, with $70-80 \%$ of these patients remaining in remission throughout the gestational period [24]. If an exacerbation occurs it is likely to be mild and responsive to medical treatment. In patients with active disease at conception, about $45 \%$ will deteriorate, $25 \%$ will improve and $25 \%$ will remain unchanged, therefore about 3 out of 4 will have active disease during their pregnancy, resulting in adverse perinatal outcomes [24].

The risk of postpartum disease relapse is partly determined by disease activity at the time of delivery. In a study of 324 patients, Modagam et al demonstrated that only $13 \%$ of patients with quiescent to mild disease at term experienced a flare in the puerperal period in contrast to $53 \%$ of patients with active disease at delivery [25]. However, there is evidence suggesting that pregnancy itself leads to improved control of IBD activity in the 
years following it. Castiglione et al reported reduced rates of disease relapse in the first three years after pregnancy compared to the pre-pregnancy period in UC patients $(\mathrm{p}<0.005)$ [26].

Pregnancy is safe in patients with IPAA but impaired pouch function can be experienced during pregnancy with increased daytime and nocturnal stool frequency and incontinence. However, pouch function tends to return to pre-pregnancy function following delivery [27].

\subsection{Mode of delivery in UC}

The observed rates of caesarean section in UC is higher than the general population [27]. The reason for this is unknown. The decision to proceed to cesarean section should be made purely on obstetric grounds except in cases where the patient has undergone IPAA. Such patients can have normal vaginal deliveries without damaging the pouch [28], however there is concern for damage to the anal sphincter. The risk of anal sphincter damage is compounded by aging, therefore the effects may not become apparent for several years. Although the current reports of IPAA patients who have had vaginal deliveries demonstrate no irreversible pouch complications in the majority of patients, there is no long-term followup data available (i.e. 20-30 years). Therefore, the decision on mode of delivery in IPAA patients should be made following detailed discussion of the potential effects on pouch and anal function by the patient, obstetrician and colorectal surgeon.

\subsection{Medications for the treatment in UC and pregnancy}

Patients are often concerned about the potential teratogenecity of the drugs used in UC and may even opt to discontinue their maintenance therapy during pregnancy. Experience and data support the safe use of many maintenance drugs during pregnancy. In fact, disease relapses and continued disease activity during pregnancy as a result of either cessation of maintenance therapy or/and avoiding induction therapy are more harmful to both the mother and the unborn baby [29]. Patients should be counseled prior to pregnancy regarding the potential toxicity of some of their medications, however they should be advised to maintain safe medical treatment for adequate control of disease activity during pregnancy. The risk of maternal drug exposure to fetal development is classified by the Food and Drug Administration (FDA) into categories, see table 1. The FDA pregnancy categories of drugs used in UC are summarized in table 2.

\section{Aminosalicylates \& sulphasalazine}

5 ASA preparations are frequently used as first line maintenance therapy for UC. They have been in use for decades with numerous studies supporting their safe use in pregnant patients. The FDA currently classifies them as pregnancy category B. Although 5 ASAs are poorly absorbed from the gastrointestinal tract, they do cross the placenta once they reach systemic circulation [30]. No consistent teratogenic effect has been demonstrated in animal and human studies. In a prospective cohort study of 60 pregnant IBD patients, Norgard et al found no substantial increased risk of malformations in patients who received 5ASAs during the first trimester of pregnancy, odds ratio 1.9 (95\% confidence interval 0.7-5.4) [31], but observed an increased risk of stillbirths and preterm deliveries which could be due to the disease rather than the drugs as the controls used were women without IBD. A metaanalysis of 7 studies, that included 2200 pregnant women with IBD; 642 received 5-ASA 
drugs (mesalazine, sulfasalazine or olsalazine) and 1158 received no medication, suggested only a 1.16-fold increase in congenital malformations, a 2.38-fold increase in stillbirth, a 1.14fold increase in spontaneous abortion, a 1.35-fold increase in preterm delivery, and a 0.93 fold increase in low birth weight [32].

\section{FDA Pharmaceutical Pregnancy Categories}

\begin{tabular}{l|l|}
\hline $\begin{array}{l}\text { Pregnancy } \\
\text { Category } \\
\text { A }\end{array}$ & $\begin{array}{l}\text { Adequate and well-controlled human studies have failed to demonstrate a risk } \\
\text { to the fetus in the first trimester of pregnancy (and there is no evidence of risk } \\
\text { in later trimesters) }\end{array}$ \\
\hline $\begin{array}{l}\text { Pregnancy } \\
\text { Category } \\
\text { B }\end{array}$ & $\begin{array}{l}\text { Animal reproduction studies have failed to demonstrate a risk to the fetus and } \\
\text { there are no adequate and well-controlled studies in pregnant women OR } \\
\text { Animal studies have shown an adverse effect, but adequate and well- } \\
\text { controlled studies in pregnant women have failed to demonstrate a risk to the } \\
\text { fetus in any trimester. }\end{array}$ \\
\hline $\begin{array}{l}\text { Pregnancy } \\
\text { Category }\end{array}$ & $\begin{array}{l}\text { Animal reproduction studies have shown an adverse effect on the fetus and there } \\
\text { are no adequate and well-controlled studies in humans, but potential benefits } \\
\text { may warrant use of the drug in pregnant women despite potential risks. }\end{array}$ \\
\hline $\begin{array}{l}\text { Pregnancy } \\
\text { Category } \\
\text { D }\end{array}$ & $\begin{array}{l}\text { There is positive evidence of human fetal risk based on adverse reaction data } \\
\text { from investigational or marketing experience or studies in humans, but potential } \\
\text { benefits may warrant use of the drug in pregnant women despite potential risks. }\end{array}$ \\
\hline $\begin{array}{l}\text { Pregnancy } \\
\text { Category } \\
\text { X }\end{array}$ & $\begin{array}{l}\text { Studies in animals or humans have demonstrated fetal abnormalities and/or } \\
\text { there is positive evidence of human fetal risk based on adverse reaction data } \\
\text { from investigational or marketing experience, and the risks involved in use of } \\
\text { the drug in pregnant women clearly outweigh potential benefits. }\end{array}$ \\
\hline
\end{tabular}

Table 1. FDA drug category during pregnancy

\begin{tabular}{|l|l|l|l|}
\hline FDA B & FDA C & FDA D & FDA X \\
\hline 5 ASAs & Corticosteroids & Azathioprine & Methotrexate \\
Amoxicillin/ Clav & Ciprofloxacin & Mercaptopurine & \\
Metronidazole & Cyclosporin & Lomotil & \\
Infliximab & Loperamide & & \\
Adalimumab & & & \\
\hline
\end{tabular}

Table 2. FDA pregnancy category of drugs used for UC

Sulfasalazine was initially thought to be teratogenic, however more recent studies failed to identify significant association between the drug and congenital anomalies [33, 34]. Sulfasalazine interacts with the cell membrane transporter for natural folates and interferes with folate absorption, which in turn may lead to folate deficiency with increased risk of neural tube defects and cardiovascular defects [35, 36]. Therefore folate supplementation with up to $2 \mathrm{mg}$ of folic acid daily should be strongly recommended to female patients on 
sulfalazine even prior to pregnancy [37]. Alternatively, patients could be switched to mesalamine, but they should still be advised to take 400 micrograms of folic acid daily when planning to conceive.

\section{Corticosteroids}

Corticosteroids are indicated for induction of disease remission during exacerbations of UC. The FDA classifies them as pregnancy category $C$. Their use in pregnancy has been associated with increased risk of cleft palate in a number of case control studies $[38,39]$. In a prospective control study of 311 pregnant IBD patients, Gur et al found no significant difference in the rate of major anomalies between the group treated with corticosteroids (GCS) during pregnancy compared to the control group [12/262 $=4.6 \%$ (GCS), $19 / 728=$ $2.6 \%$ (control), $[\mathrm{P}=0.116]$. There was no case of oral cleft and no pattern of anomalies among the GCS exposed group [40].

Corticosteroids can cross the placenta but the rate varies with the type of steroid depending on the extent of placental metabolism and placental and albumin binding affinity [41]. Fetal exposure to prednisolone is lower than for other steroids such as dexamethasone, and should therefore be used in preference to them during pregnancy [42, 43].

\section{Immunosuppressants}

Escalation of maintenance medical treatment to immunosuppressants is required in patients with moderate to severe refractory UC. This category includes azathioprine (AZA), mercaptopurines (MP), and methotrexate (MTX). The first two drugs are classified by the FDA as category D drugs, but MTX is classified as category $X$, and patients should be advised not to conceive on the drug or even within 3 months of stopping it, as it is associated with a high risk of developing craniofacial deformities, limb defects and severe central nervous system abnormalities [44].

AZA/MP are relatively less toxic during pregnancy in humans although animal studies have demonstrated an increased risk of teratogenecity with their use [15]. The oral bioavailability of the two drugs is low (47\% for AZA and $16 \%$ for MP)(44), and their placental transfer is limited [45]. AZA/MP are absorbed in their inactive form and the fetal liver lacks the enzyme necessary to convert them to the active and potentially toxic metabolites [46]. Case reports of the teratogenic effects of AZA use during pregnancy such as chromosomal abnormalities and myelotoxicity in the infant originate from transplant and oncology patients using higher doses of the drug than would be used in UC [47]. AZA is used at a dose of $1-1.5 \mathrm{mg} / \mathrm{kg}$ of body weight in patients with UC, and studies on its effects during pregnancy at this dose have found no increased risk of teratogenicity [48- 50]. In a large retrospective review of 325 pregnancies, Francella et al showed that the use of AZA/ $\mathrm{MP}$ prior to, at conception and during pregnancy does not increase the risk of spontaneous abortions, stillbirths, prematurity or the rate of neonatal or childhood infections [17]. Shim et al reported the safe use of AZA /MP in pregnant IBD patients in Australia. In 19 births exposed to AZA / MP there was 1 neonatal adverse outcome in the exposed group as compared to 4 in controls ( $5.3 \%$ vs. $5.4 \%, p=0.97)$. One congenital anomaly was seen in each group ( $\mathrm{p}=0.27$ ). No low birth weight at term was seen in either group. Placental blood flow in 4 women exposed to AZA / MP was normal [51]. In a large cohort from the CESAME study, Coelho et al found no significant difference in overall pregnancy outcomes between pregnancies exposed to thiopurines $(n=86)$ and those not exposed to any treatment $(n=45)$ [52]. 
Cyclosporin (CYA) is indicated in patients with fulminant colitis or severe exacerbations of UC unresponsive to induction therapy with steroids. It is classified as FDA category C. It is only $34 \%$ absorbed from the gastrointestinal tract, but can cross the placenta [53]. Animal studies found some fetal toxicity associated with exposure to the drug at maternotoxic doses including embryo lethality, and reduced fetal growth [54]. Reports of its use in humans during pregnancy come from transplant patients. A meta-analysis of 15 studies that included 410 patients failed to identify any significant teratogenicity associated with the use of CYA. The rates of prematurity and low birth weight were higher in infants exposed to CYA, but did not reach statistical significance [55]. In cases of fulminant colitis the use of CYA may preclude the need for colectomy. Colectomy resulted in fetal loss in 2 of 4 pregnant patients who underwent surgery for fulminant colitis in a case series by Anderson et al [56].

\section{Biologic agents}

Anti TNFa therapy was initially used in refractory and fistulating CD, but there is increasing evidence to support its use in UC. Naturally there were numerous concerns for their potential toxicity in pregnancy, however recent studies have demonstrated their safety during pregnancy. A case series of 4 pregnant IBD patients who continued their infliximab (IFX) treatment during pregnancy by Zolinkova et al, reported therapeutic IFX levels in the cord blood of 3 babies at levels 2-3 fold higher than in the peripheral blood of the their mothers, and during the 3- to 6-month follow-up, the children developed normally without signs of infections or allergic reactions, and had normal antibody titres after routine childhood vaccinations [57]. A larger observational study by Schnitzler et al, assessed 212 IBD patients on anti TNFa treatment and found that 32 of the 42 pregnancies ended in live births with a median gestational age of 38 weeks (interquartile range [IQR] 37-39). There were seven premature deliveries, six children had low birth weight, and there was one stillbirth. One boy weighed $1640 \mathrm{~g}$ delivered at week 33, died at age 13 days secondary to necrotizing enterocolitis. A total of eight abortions (one patient wish) occurred in seven women. Trisomy 18 was diagnosed in one foetus of a mother with $\mathrm{CD}$ at age 37 years under adalimumab (ADA) treatment (40 mg weekly) and pregnancy was terminated. Pregnancy outcomes after direct exposure to anti-TNFa treatment were not different from those in pregnancies before anti-TNFa treatment or with indirect exposure to anti-TNFa treatment but outcomes were worse than in pregnancies before IBD diagnosis [58]. Anti TNFa drugs are classified as pregnancy category B by the FDA.

Although data supports the safe use of biologic therapy in UC patients during pregnancy, we must be aware of the potential complications of immunosuppression in babies born to mothers receiving anti TNFa treatment during the third trimester of pregnancy. Cheent et al reported a case of an infant born to a mother who received IFX throughout her pregnancy, dying of disseminated TB infection at age 4.5 months after receiving BCG vaccination at the age of 3 months. Live attenuated vaccines including BCG are contraindicated in individuals who are receiving immunosuppressive drugs, and physicians should exercise caution before such vaccines are used in infants born to mothers taking anti-TNF therapies or other potentially immunosuppressive IgG1 antibodies [59]. Consideration should be given to the cessation of biologic treatment in the third trimester of pregnancy to reduce foetal exposure to the drug immediately prior to delivery. 


\section{Antibiotics}

Antibiotics such as metronidazole and ciprofloxacin have limited use in UC. Their shortterm use for the treatment of pouchitis post IPAA is considered low risk in pregnancy. Metronidazole is classified as FDA pregnancy category B. Its use in pregnancy has not been associated with increased risk of congenital abnormalities. A retrospective review by Sorensen et al demonstrated no increased preterm delivery following metronidazole treatment during pregnancy in a cohort of 124 patients [60]. Diav-Citrin et al prospective studied 228 women exposed to metronidazole during pregnancy and found no significant difference between the cases and controls in terms of congenital abnormalities and preterm delivery, however the mean birth weight was lower in the treatment group [61]. Amoxicillin/ clavulanic acid is an FDA category B drug and is considered safe during pregnancy.

Ciprofloxacin and other quinolones are classified as FDA pregnancy category C drugs. In a prospective review of 200 patients treated with quinolones during pregnancy, Loebstein et al failed to show an increased risk of arthropathy demonstrated in animal studies [62]. There was no significant increased rate of spontaneous abortions, prematurity or birth weight in the treatment group. Sulphonamides and tetracyclines are contraindicated in pregnancy.

\section{Anti-diarrheals}

Anti-diarrheal agents are used for symptomatic relief during pregnancy. Loperamide is classified as FDA category B drug. In a prospective case control study of 105 women, Einarson et al found no increased risk of miscarriage, preterm delivery or congenital anomalies with the use of loperamide intermittently during pregnancy [63]. However, a Lower mean birth weight was documented in infants whose mothers received loperamide continuously during pregnancy. Another study of 638 pregnancies exposed to loperamide from early pregnancy showed an increased rate of congenital defects (OR 1.41; 97\% CI 1.03 1.93); only hypospadias showed a significant increase ( $R R=3.2,95 \%$ CI 1.3 - 6.6) [64]. Lomotil (diphenoxylate hydrochloride/atropine) is classified as FDA category C drug. It should be used with caution in pregnant patients, as it is not known whether it can cross the placenta.

\section{UC and breastfeeding}

Breastfeeding has well-recognized benefits to infants, including reducing the risk of developing IBD in later life [65]. It has not been shown to influence the pattern of UC disease activity in the post partum period [66]. However, patients are often concerned about the potential toxicity of pharmacological UC therapy to the breastfed infant. Patients should be offered individual advice regarding whether or not to breastfeed depending on the benefit/ risk ratio of the prescribed medication on the infant, and the risk of cessation of medical therapy to the mother.

Sulphasalazine and other 5ASAs are relatively safe during breastfeeding as less than $10 \%$ of the maternal dose is excreted in breast milk [67], however there are two case reports in the literature describing diarrhea in a breastfed infant whose mother was being treated with sulphasalazine $[68,69]$. There are no other studies demonstrating adverse effects of 5ASAs on breastfed infants, therefore UC patients should be encouraged to breastfeed while on aminosalicylates. 
Only 5 - $25 \%$ of maternal plasma steroid concentrations are present in breast milk [70], therefore infant exposure to the drug is very low. There are no reports of harmful effects on infants breastfed by mothers taking corticosteroids, however patients should be advised to delay breastfeeding by 4 hours following administration of steroids to decrease infant exposure to the drug since its half life is 3 hours [71].

Immunosuppressants are secreted in breast milk and can potentially suppress the infant's immune system. Clinical experience suggests that AZA and MP are safe to use while breastfeeding. In a retrospective review of nursing mothers taking AZA, Angelberger et al demonstrated that the infants had age appropriate mental status and physical development compared to the control group with no difference in the rate of hospitalization [72]. CYA and MTX should be avoided by nursing mothers due to the risk of infant immunosuppression, potential harmful effects on growth, and association with carcinogenesis [73]. There is limited data describing the use of biologic drugs during lactation. In a small case series of 3 mothers treated with IFX during the post partum period, Kane et al found no detectable levels of IFX in the breast milk or the sera of the breastfed infants [74]. This suggests that mothers on IFX should not be discouraged from breastfeeding. It is not known whether ADA is secreted in breast milk and should therefore be avoided in nursing mothers.

Amoxicillin/ clavulanic acid is safe to use in nursing mothers [75], however there is limited data regarding metronidazole and ciprofloxacin, and they should be avoided during breastfeeding. Loperamide and diphenoxylate hydrochloride are excreted in breast milk and should be avoided in nursing mothers [70]. See table 3 for the summary of drug safety during breastfeeding.

\begin{tabular}{|l|l|l|l|}
\hline Low risk & Limited data & Not recommended & Contraindicated \\
\hline $\begin{array}{l}\text { Steroids } \\
\text { Mesalamine }\end{array}$ & Adalimumab & Metronidazole & Methotrexate \\
$\begin{array}{l}\text { Sulphasalazine } \\
\text { Amoxicillin/ } \\
\text { clavulanic acid }\end{array}$ & Cyprofliximab & Azathioprine & \\
\hline
\end{tabular}

Table 3. Safety of drugs during breastfeeding

\section{Summary}

Patients with UC should be reassured that the diagnosis of UC does not necessarily imply impaired fertility and/or increased risk of congenital and developmental abnormalities in the baby. Impaired fertility is related to disease activity, pharmacological agents used for medical management, and/or surgery for UC (IPAA). Active UC at conception is associated with increased risk of gestational disease activity and exacerbations, which in turn is associated with increased risk of adverse pregnancy outcomes. Although certain drugs used for the treatment of UC such as MTX are potentially teratogenic and are contraindicated prior to and during pregnancy, the majority of them are relatively safe, including immunosuppressants and biologic agents. Clinical experience has demonstrated 
that disease activity during pregnancy is more harmful to both the mother and the baby than the majority of drugs used to treat exacerbations, and / or maintain remission of UC during pregnancy.

UC patients should be advised to attempt to conceive during periods of disease remission. The potential toxicity of medical treatment in pregnancy should be discussed, and the benefit / risk ratio estimated on an individual basis.

UC patients should not be discouraged from breastfeeding their infants, however the potential toxicity of the mother's medications should be taken into consideration and the risk to the baby weighed against the risk of disease relapse in the mother if medical treatment was discontinued.

\section{Expert opinion}

The second European evidence-based consensus on the diagnosis and management of inflammatory bowel disease (IBD) published the following statements in relation to IBD and pregnancy [76]:

IBD and fertility:

- IBD does not seem to affect fertility when the disease is inactive, however disease activity leads to reduced fertility.

- Female patients who undergo surgery are at risk of impaired tubal function.

- In male patients rectal excision may cause impotence of ejaculatory problems, however there is no comparison with the general population.

- Sulphasalazine therapy causes reversible infertility in male patients because of changes in semen quality.

IBD and pregnancy:

- It is advisable to strive for clinical remission before conception.

- If conception occurs at a time of quiescent disease the risk of relapse is the same as on non-pregnant women.

- If conception occurs at a time of disease activity, two thirds have persistent activity, and of these two thirds deteriorate.

- $\quad$ Flares are best treated aggressively to prevent complications.

- Insufficient data exists about maternal morbidity and fetal mortality at surgery.

- Both clinical activity and surgical intervention decline with pregnancy and parity.

Mode of delivery:

- The mode of delivery should primarily be governed by obstetric necessity and indication, but also in conjunction with the gastroenterologist and/or colorectal surgeon.

- An ileo-anal pouch is regarded as an indication for caesarean section.

- Colostomy or ileostomy patients can deliver vaginally.

Medical treatment during pregnancy:

- Medical treatment for IBD should generally continue during pregnancy, because the benefits outweigh the risk of medication.

\section{References}

[1] Narendranathan M, Sandler RS, Suchindran CM, et al. Male infertility in inflammatory bowel disease. J Clin Gastroenterol 1989;11:403-6. 
[2] Moody GA, Probert C, Jayanthi V, Mayberry JF. The effects of chronic ill health and treatment with sulphasalazine on fertility amongst men and women with inflammatory bowel disease in Leicestershire. Int J Colorectal Dis 1997; 12: 220-4.

[3] Hueting WE, Gooszen HG, Van Laarhoven CJ. Sexual function and continence after ileo pouch anal anastomosis: a comparison between a meta-analysis and a questionnaire survey. Int J Colorectal Dis 2004; 19: 215-8.

[4] Berndtsson I, Oresland T, Hulten L. Sexuality in patients with ulcerative colitis before and after restorative proctocolectomy: a prospective study. Scand J Gastroenterol 2004; 39: 374-9.

[5] Gorgun E, Remzi FH, Montague DK, Connor JT, O'Brien K, Loparo B, Fazio VW. Male sexual function improves after ileal pouch anal anastomosis. Colorectal Dis. 2005 Nov;7(6):545-50.

[6] De Dombal FT, Watts JM, Watkinson G, Goligher JC. Ulcerative colitis and pregnancy. Lancet 1965; 25: 599-602.

[7] Olsen KO, Juul S, Berndtsson I, et al. Ulcerative colitis: female fecundity before diagnosis, during disease, and after surgery compared with a population sample. Gastroenterology 2002;122:15-19.

[8] Johnson P, Richard C, Ravid A, et al. Female infertility after ileal pouch-anal anastomosis for ulcerative colitis. Dis Colon Rectum 2004;47:1119-26.

[9] Levi AJ, Fisher AM, Hughes L, Henry WF. Male infertility due to sulphasalazine. Lancet $1979 ; 314: 276-8$.

[10] O'Morain C, Smethurst P, Dore CJ, Levi AJ. Reversible male infertility due to sulphasalazine: studies in man and rat. Gut 1984; 25:1078-84.

[11] Zelissen PM, Van Hattum J, Poen H, Scholten P, Gerritse R, Te Velde ER. Influence of salazosulphapyridine and 5-aminosalicylic acid on seminal qualities and male sex hormones. Scand J Gastroenterol 1988; 23: 1100-4

[12] Balasubramanian K, Aruldhas MM, Govindarajulu P. Effect of corticosterone on rat epididymal lipids. J Androl 1987; 8: 69-73.

[13] Lerman SA, Miller GK, Bohlman K, et al. Effects of corticosterone on reproduction in male Sprague-Dawley rats. Reprod Toxicol 1997; 11: 799- 805.

[14] Roberts AC, McClure RD, Weiner RI, Brooks GA. Overtraining affects male reproductive status. Fertil Steril 1993; 60: 686-92.

[15] Polifka JE, Friedman JM. Teratogen update: azathioprine and 6- mercaptopurine. Teratology 2002;65:240-61.

[16] Dejaco C, Mittermaier C, Reinisch W, et al. Azathioprine treatment and male fertility in inflammatory bowel disease. Gastroenterology 2001; 121: 1048-53.

[17] Francella A, Dyan A, Bodian C, Rubin P, Chapman M, Present DH. The safety of 6mercaptopurine for childbearing patients with inflammatory bowel disease: a retrospective cohort study. Gastroenterology 2003; 124: 9-17.

[18] Xu L, Han S, Liu Y, Wang H, et al. The influence of immunosuppressants on the fertility of males who undergo renal transplantation and on the immune function of their offspring. Transpl Immunol. 2009 Dec;22(1-2):28-31.

[19] Treacy G. Using an analogous monoclonal antibody to evaluate the reproductive and chronic toxicity potential for a humanized anti-TNF-a monoclonal antibody. Hum Exp Toxicol 2000;19: 226-8. 
[20] Norgard B, Fonager K, Sorensen H T. et al Birth outcomes of women with ulcerative colitis: a nationwide Danish cohort study. Am J Gastroenterol 2000. 953165-3170.

[21] Fedorkow D M, Persaud D, Nimrod C A. Inflammatory bowel disease: a controlled study of late pregnancy outcome. Am J Obstet Gynecol 1989. 160998-1001.

[22] Bush M C, Patel S, Lapinski R H. et al Perinatal outcomes in inflammatory bowel disease. J Matern Fetal Neonatal Med 2004. 15237-241.

[23] Kornfeld D, Cnattingius S, Ekbom A. Pregnancy outcomes in women with inflammatory bowel disease - a population-based cohort study. Am J Obstet Gynecol 1997. 177942-946.

[24] Miller JP. Inflammatory bowel disease in pregnancy: a review. J R Soc Med 1986;79:2215.

[25] Mogadam M, Korelitz BI, Ahmed SW, Dobbins WO, 3rd, Baiocco PJ. The course of inflammatory bowel disease during pregnancy and post partum. Am J Gastroenterol 1981a; 75: 265-9.

[26] Castiglione F, et al. Effect of pregnancy on the clinical course of a cohort of women with inflammatory bowel disease. Ital J Gastroenterol. 1996 May;28(4):199-204.

[27] Ravid A, Richard CS, Spencer LM, et al. Pregnancy, delivery and pouch function after ileal pouch-anal anastomosis for ulcerative colitis. Dis Colon Rectum 2002; 45: $1283-$ 8.

[28] Juhasz ES, Fozard B, Dozois RR, Ilstrup DM, Nelson H. Ileal pouch-anal anastomosis function following childbirth: an extended evaluation. Dis Colon Rectum 1995; 38: 159-65.

[29] Moffatt DC, Bernstein CN. Drug therapy for inflammatory bowel disease in pregnancy and the puerperium. Best Pract Res Clin Gastroenterol. 2007;21(5):835-47.

[30] Christensen LA, Rasmussen SN, Hansen SH. Disposition of 5-aminosalicylic Acid and $\mathrm{N}$-acetyl-5-aminosalicylic acid in fetal and maternal body-fluids during treatment with different 5-aminosalicylic acid preparations. Acta Obstet Gynecol Scand, 1994;73:399-40.

[31] Norgard B, Fonager K, Pedersen L, et al. Birth outcome in women exposed to 5aminosalicylic acid during pregnancy: a Danish cohort. study Gut 2003;52:243-7.

[32] Rahimi R, Nikfar S, Rezaie A, et al. Pregnancy outcome in women with inflammatory bowel disease following exposure to 5-aminosalicylic acid drugs: a meta-analysis. Reprod Toxicol2008;25:271-5.

[33] Hoo JJ, Hadro TA, Von Behren P. Possible teratogenicity of sulfasalazine. N Engl J Med 1988;318:1128.

[34] Norgard B, Czeizel AE, Rockenbauer M, et al. Population-based case control study of the safety of sulfasalazine use during pregnancy. Aliment Pharmacol Ther, 2001;15:483-6.

[35] Jansen G, Van der Heijden J, Oerlemans R, et al. Sulfasalazine is a potent inhibitor of the reduced folate carrier: implications for combination therapies with methotrexate in rheumatoid arthritis. Arthritis Rheum 2004; 50: 2130-9.

[36] Czeizel AE, Toth M, Rockenbauer M. Population-based case control study of folic acid supplementation during pregnancy.Teratology 1996; 53: 645-51.

[37] Mahadevan U, Kane S. American Gastroenterological Association Institute Technical Review on the use of gastrointestinal medications in pregnancy. Gastroenterology 2006; 131: 283-311. 
[38] Rodriguez-Pinilla E, Martinez-Frias ML. Corticosteroids during pregnancy and oral clefts: a case-control study. Teratology 1998;58: 2-5.

[39] Carmichael SL, Shaw GM. Maternal corticosteroid use and risk of selected congenital anomalies. Am J Med Genet 1999; 86:242-4.

[40] Gur C, Diav-Citrin O, Shechtman S, Arnon J, Ornoy A. Pregnancy outcome after first trimester exposure to corticosteroids: a prospective controlled study. Reprod Toxicol 2004; 18: 93-101.

[41] Review article: Reproduction in the patient with inflammatory bowel disease. Heetun ZS, Byrnes C, Neary P, O'Morain C. Aliment Pharmacol Ther. 2007 Aug 15;26(4):51333.

[42] Blanford AT, Murphy BE. In vitro metabolism of prednisolone, dexamethasone, betamethasone, and cortisol by the human placenta. Am J Obstet Gynecol 1977; 127: 264-7.

[43] Dancis J, Jansen V, Levitz M. Placental transfer of steroids: effect of binding to serum albumin and to placenta. Am J Physiol 1980;238: E208-13.

[44] Milunsky A, Graef JW, Gaynor MF Jr. Methotrexate-induced congenital malformations. J Pediatr 1968; 72: 790-5.

[45] De Boer NK, Jarbandhan SV, De Graaf P, Mulder CJ, Van Elburg RM, Van Bodegraven AA. Azathioprine use during pregnancy: unexpected intrauterine exposure to metabolites. Am J Gastroenterol 2006; 101: 1390-2.

[46] Janssen NM, Genta MS. The effects of immunosuppressive and anti-inflammatory medications on fertility, pregnancy, and lactation. Arch Intern Med 2000; 160: 610-9.

[47] Davison JM, Dellagrammatikas H, Parkin JM. Maternal azathioprine therapy and depressed haemopoiesis in the babies of renal allograft patients. Br J Obstet Gynecol 1985; 92: 233-9.

[48] Norgard B, Pedersen L, Fonager K, Rasmussen SN, Sorensen HT. Azathioprine, mercaptopurine and birth outcome: a population-based cohort study. Aliment Pharmacol Ther 2003; 17: 827-34.

[49] Alstead EM, Ritchie JK, Lennard-Jones JE, Farthing MJ, Clark ML. Safety of azathioprine in pregnancy in inflammatory bowel disease. Gastroenterology 1990; 99: 443-6.

[50] Oefferlbauer-Ernst A, Reinisch W, Miehsler W, Vogelsang H, Dejaco C. Healthy offspring in parents both receiving thiopurines. Gastroenterology 2004; 126: 628.

[51] Shim L, Eslick GD, Simring AA, Murray H, Weltman MD.The effects of azathioprine on birth outcomes in women with inflammatory bowel disease (IBD). J Crohns Colitis. 2011 Jun;5(3):234-8.

[52] Coelho J, et al. Pregnancy outcome in patients with inflammatory bowel disease treated with thiopurines: cohort from the CESAME Study.; CESAME Pregnancy Study Group (France). Gut. 2011 Feb;60(2):198-203.

[53] Albengres E, Le Louet H, Tillement JP. Immunosuppressive drugs and pregnancy: experimental and clinical data. Transplant Proc1997; 29: 2461-6.

[54] Mason RJ, Thomson AW, Whiting PH, et al. Cyclosporine-induced fetotoxicity in the rat. Transplantation 1985;39:9-12.

[55] Bar Oz B, Hackman R, Einarson T, Koren G. Pregnancy outcome after cyclosporine therapy during pregnancy: a meta-analysis. Transplantation. 2001 Apr 27;71(8):10515. 
[56] Anderson JB, Turner GM, Williamson RC. Fulminant ulcerative colitis in late pregnancy and the puerperium. J $R$ Soc Med 1987;80: 492-4.

[57] Zelinkova Z, et al. High intra-uterine exposure to infliximab following maternal antiTNF treatment during pregnancy. Aliment Pharmacol Ther. 2011 May;33(9):1053-8.

[58] Schnitzler F, et al. Outcome of pregnancy in women with inflammatory bowel disease treated with antitumor necrosis factor therapy. Inflamm Bowel Dis. 2011 Jan 6. [Epub ahead of print].

[59] Cheent K et al Case Report: Fatal case of disseminated BCG infection in an infant born to a mother taking infliximab for Crohn's disease. J Crohns Colitis. 2010 Nov;4(5):603-5.

[60] Sorensen HT, Larsen H, Jensen ES, et al. Safety of metronidazole during pregnancy: a cohort study of risk of congenital abnormalities, preterm delivery and low birth weight in 124 women. J Antimicrob Chemother 1999; 44: 854-6.

[61] Diav-Citrin O, Shechtman S, Gotteiner T, Arnon J, Ornoy A. Pregnancy outcome after gestational exposure to metronidazole: a prospective controlled cohort study. Teratology 2001; 63: 186-92.

[62] Loebstein R, Addis A, Ho E, et al. Pregnancy outcome following gestational exposure to fluoroquinolones: a multicenter prospective controlled study. Antimicrob Agents Chemother 1998; 42: 1336-9.

[63] Einarson A, Mastroiacovo P, Arnon J, et al. Prospective, controlled, multicentre study of loperamide in pregnancy. Can J Gastroenterol 2000; 14: 185-7.

[64] Kallen B, Nilsson E, Olausson PO. Maternal use of loperamide in early pregnancy and delivery outcomes. Acta Paediatrica 2008;97:541-5.

[65] Bergstrand O, Hellers G. Breast-feeding during infancy in patients who later develop Crohn's disease. Scand J Gastroenterol 1983; 18: 903-6.

[66] Kane S, Lemieux N. The role of breastfeeding in postpartum disease activity in women with inflammatory bowel disease. Am J Gastroenterol 2005; 100: 102-5.

[67] Silverman DA, Ford J, Shaw I, Probert CS. Is mesalazine really safe for use in breastfeeding mothers? Gut 2005; 54: 170-1.

[68] Branski D, Kerem E, Gross-Kieselstein E, Hurvitz H, Litt R, Abrahamov A. Bloody diarrhea - a possible complication of sulfasalazine transferred through human breast milk. J Pediatr Gastroenterol Nutr 1986; 5: 316-7.

[69] Nelis G. Diarrhoea due to 5-aminosalicylic acid in breast milk. Lancet 1989; i: 383.

[70] Ferrero S, Ragni N. Inflammatory bowel disease: management issues during pregnancy. Arch Gynaecol Obstet 2004; 270: 79-85.

[71] Jusko WJ. Pharmacokinetics and receptor-mediated pharmacodynamics of corticosteroids. Toxicology 1995; 102: 189-96.

[72] Angelberger S, et al. Long term follow-up of babies exposed to azathioprine in utero and $b=$ via breast feeding. J Crohns Coliltis, 2011. Apr;5(2):95-100.

[73] Committee on Drugs American Academy of Pediatrics. Transfer of drugs and other chemicals into human milk. Pediatrics 2001; 108: 776-9.

[74] Kane et al. Absence of infliximab in infants and breast milk from nursing mothers receiving therapy for Crohn's disease before and after delivery. J Clin Gastroenterol. 2009; 43: 613-616. 
[75] Mahadevan U, Kane S. American Gastroenterological Association Institute Technical Review on the use of gastrointestinal medications in pregnancy. Gastroenterology 2006; 131: 283-311.

[76] Gert Van Assche, Axel Digness, Walter Reinisch, et al. The second European evidencebased consensus on the diagnosis and management of Crohn's Disease: special situations. Journal of Crohn's and Colitis (2010)4,63-101. 


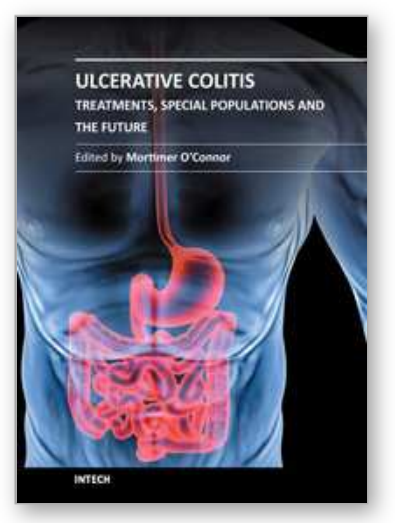

\author{
Ulcerative Colitis - Treatments, Special Populations and the Future \\ Edited by Dr Mortimer O'Connor
}

ISBN 978-953-307-739-0

Hard cover, 178 pages

Publisher InTech

Published online 02, November, 2011

Published in print edition November, 2011

This book is intended to act as an up to date reference point and knowledge developer for all readers interested in the area of gastroenterology and in particular Ulcerative Colitis. All of the chapter authors are experts in their fields of publication and deserve individual credit and praise for their contributions to the world of Ulcerative Colitis. We hope that you will find this publication informative, stimulating and a reference point for the area of Ulcerative colitis as we move forward in our understanding of the field of medicine.

\title{
How to reference
}

In order to correctly reference this scholarly work, feel free to copy and paste the following:

A. Alakkari and C. O'Morain (2011). Ulcerative Colitis and Pregnancy, Ulcerative Colitis - Treatments, Special Populations and the Future, Dr Mortimer O'Connor (Ed.), ISBN: 978-953-307-739-0, InTech, Available from: http://www.intechopen.com/books/ulcerative-colitis-treatments-special-populations-and-the-future/ulcerativecolitis-and-pregnancy

\section{INTECH}

open science | open minds

\author{
InTech Europe \\ University Campus STeP Ri \\ Slavka Krautzeka 83/A \\ 51000 Rijeka, Croatia \\ Phone: +385 (51) 770447 \\ Fax: +385 (51) 686166 \\ www.intechopen.com
}

\author{
InTech China \\ Unit 405, Office Block, Hotel Equatorial Shanghai \\ No.65, Yan An Road (West), Shanghai, 200040, China \\ 中国上海市延安西路65号上海国际贵都大饭店办公楼 405 单元 \\ Phone: +86-21-62489820 \\ Fax: $+86-21-62489821$
}


(C) 2011 The Author(s). Licensee IntechOpen. This is an open access article distributed under the terms of the Creative Commons Attribution 3.0 License, which permits unrestricted use, distribution, and reproduction in any medium, provided the original work is properly cited. 